\title{
La política como moral
}

\author{
VICTORIA CAMPS
}

\section{1. Ética y política}

En el año 1963, dos años antes de ser expulsado de la Universidad, Aranguren se embarca en la empresa de un seminario sobre «Ética y política». En apariencia, el seminario se propone abordar la manida cuestión - no tan manida entonces, entre nosotros, como ha llegado a serlo luego- de la imposible relación entre la ética y la política: ¿́realismo maquiavélico?, íncompatibilidad trágica de estilo sartriano?, iincompatibilidad dramática? Tales preguntas son, en efecto, el punto de partida. Pero la intención del seminario, luego libro ${ }^{1}$, es más original y defiende una tesis más arriesgada. Aranguren se propone desarrollar y justificar nada menos que la «institucionalización» de la moral por la política. La idea de que no basta quedarse con una moral personal, de la conciencia, no: la moral debe «socializarse», convertirse en una empresa colectiva, común y compartida. La política ha de unirse a la ética: ética y política.

Si tomamos como punto de referencia la distinción kantiana entre «la moral política» y «la política moral», junto a la valoración que Kant hace de ambas posibilidades, no hay duda de que Aranguren opta por la propuesta kantiana. Una moral política sería una aberración, mientras una política moral es, precisamente, el fin que debemos desear para la política. Leamos el fragmento de La paz perpetua: «puedo concebir un politico moral, es decir, un político que entiende los principios de la habilidad política de modo que puedan coexistir con la moral, pero no un moralista político, que se forje una moral útil a las conveniencias del hombre de Estado» ${ }^{2}$. Esto es, la política es moralmente legítima como sujeto de la moral, nunca como un atributo que la determina para ponerla a su servicio. La política debe aspirar a ser moral; la moral no debe condescender ante los condicionantes de la política.

Aranguren, es cierto, no utiliza el texto kantiano. Sin embargo, su "ética de la aliedad” - a la que voy a referirme a continuación- está muy próxima a este rechazo de una política maniobrera de la moral, y a favor de una política servidora de ideales y principios morales: una política que sea de veras moral.

El tema que le interesa aclarar a Aranguren, tras haber pasado revista a las diversas teorías que cuestionan radicalmente la relación posible entre moral y política, es el de la "moralización» de la vida política. ¿Cómo podría el Estado impregnarse de moral? La primera respuesta, quizá la más obvia

'Etica y politica, Guadarrama, Madrid, 1963; Obras Completas, 3.

' I. Kant, La paz perpetua, Tecnos, p. 48. 
y convincente, es la que entiende tal moralización como un proceso de abajo arriba: moralización del Estado por los individuos o moralización del Estado por los grupos sociales. Montesquieu, Rousseau, Marx, el mismo Sartre auspiciarían esa visión cambiando, por supuesto, los nombres. La Ilustración, en efecto, se propone hacer del individuo un ciudadano, la misión del cual es la de racionalizar el Estado. Marx y el marxismo - de Sartre o de otrosauguran una transformación de la sociedad -finalmente, sin necesidad de Estado ni de aparatos coactivos de ningún tipo-- operada por la fuerza de revoluciones grupales ${ }^{3}$. A este tipo de transformación la llama Aranguren «ética de la alteridad»: el Estado es el resultado del pacto o de la revolución social.

Es una posibilidad insatisfactoria. Insatisfactoria porque el Estado parece ser un fenómeno originario, que debe tener implícito el poder de su propia transformación. Aranguren propone, en consecuencia, otra forma de entender la relación entre ética y política: la «ética de la aliedad». Como si la ética tuviera que ser una fuerza más intrínseca a la misma política. $O$ como si la ética o la moral mostraran su propia insuficiencia sin la vinculación a un proyecto originariamente comunitario social. «Como escribió Helvecio, la moral es una ciencia frívola si no se une a la política,»

¿Concesión a la eticidad hegeliana? Sólo en principio. El Estado tiene que constituirse en sujeto de la eticidad, como quiso Hegel, en efecto, pero -añade Aranguren corrigiendo el reduccionismo hegeliano- «no puede darse una eticidad pura». La moral tiene que «organizarse», «institucionalizarse», si bien al hacerlo, de algún modo, se rebaja, se «tecnifica», pierde su pureza originaria. Lo vemos, por ejemplo, tanto en el «comunismo totalitario» como en la «sociedad del bienestar» o en el «Estado de justicia social». Tres raros ejemplos puestos por el autor en un mismo saco — pensemos que estamos en los primeros sesenta-, que vienen a representar una cierta alicnación, pero alienación necesaria, de la moral. Lo que el comunismo podría tener de progreso moral, lo pierde por su sacrificio de las libertades. La sociedad del bienestar - sociedad de la abundancia, a ser exactos- es lo contrario: demasiadas concesiones al capitalismo y a la manipulación consumista. Sólo un Estado de justicia social - lo que hoy sería, si no me equivoco, el Estado de bienestar-, que haga posible una moral a la vez personal y social, merece la aprobación como muestra de una moral institucionalizada. El mensaje importante del libro es éste: «la moralización social no puede ser confiada a los individuos, ni siquiera en el plano interpersonal a la alteridad, sino que requiere ser institucionalizada, convertida en una función, en un servicio públicon ${ }^{4}$. Sólo el Estado garantiza la realización plena de la moral. Es inútil confiar únicamente en la virtud individual para la realización de un orden objetivo.

\footnotetext{
${ }^{3}$ La concepción del marxismo como una apuesta por una sociedad más justa la desarrolla Aranguren, poco después, en El marxismo como moral, Alianza, Madrid, 1968; Obras Completas, 3.

“ Ibid., p. 306.
} 


\section{La democracia como moral}

La separación de la Cátedra, la necesidad de emigrar, la necesaria dispersión, truncan la carrera estrictamente académica de Aranguren. Años más tarde dirá que ya no siente la necesidad de escribir verdaderos libros, sino de escribir al día. Así lo reconoce en la introducción a un libro de 1982 : «En otros tiempos redactaba verdaderos, indubitables libros, escritos, desde el principio, como tales, pero ahora ya no creo, "sólo en lo que a mí respecta, por supuesto" en tales libros (...). Vivo la circunstancialidad de que habla Ortega con tal intensidad, que necesito escribir, por decirlo así, al día.» Quizá sea cierto. Aranguren fue siempre un hábil especialista en hacer de la necesidad virtud. Sin que ello le coartara en absoluto sus, en ocasiones, agrias críticas y disidencias. Actuó y habló siempre desde la sinceridad de sus convicciones, sin calcular demasiado posibles consecuencias adversas para él mismo. Lo que sí es indudable es que siempre puso énfasis en la importancia de la «moral vivida» sobre la «moral docente» o enseñada en la academia. Una moral, la primera, que puede desarrollarse de muchas maneras, a través de los libros más serios y rigurosos y a través de textos más fragmentarios y periodísticos. Por obligación, tuvo que optar por lo segundo durante unos años decisivos para su carrera. Luego se acostumbró o se encontró a gusto en esa práctica que fue, sin duda, la que le valió el apelativo que no sólo no rehuyó, sino cultivó con esmero: el de intelectual moralista.

Al ser instaurada la democracia, Aranguren vuelve a la Universidad. Aparentemente, están lejos sus antiguas teorías sobre la «moral como estructura» o la «institucionalización política de la moral». Pero no es así. Aparentemente también, Aranguren se ha vuelto más polemista, más dispuesto a ventilar sus discrepancias en público. Escribe en los periódicos, da innumerables conferencias, habla por televisión, se convierte en un personaje público militantemente a la sombra de la política establecida. ¿Amargado por el tiempo que le han hecho perder? ¿Decepcionado por la España que se encuentra? ¿Desilusionado por csa transición tampoco prevista desde las expectativas progresistas? Quizá un poco de todo ello, unido a la necesidad de no abdicar de un papel de moralista activo que las circunstancias ya le han encomendado y que cumplirá a la perfección.

Releída ahora la obra que Aranguren dedica a la política, desde el primero, Ética y politica, pasando por El marxismo como moral, hasta sus muchos artículos sobre la transición política a la democracia, está muy claro que sus primeras teorías siguen firmes, se mantienen hasta el fin de su vida. Se mantienen para ponerse al servicio del análisis de la nueva realidad política que España está viviendo y experimentando. El lenguaje es menos abstracto porque ahora hay un fenómeno muy concreto al que apuntar: la transición democrática. Una

\footnotetext{
'Sobre imagen, identidad y heterodoxia, Taurus, Madrid, 1982; Obras Completas, 3.
} 
democracia incipiente, tentativa, muy imperfecta e insatisfactoria, pero por cuya causa hay que luchar. La democracia como moral es el nuevo imperativo y el baluarte de todos sus escritos sobre la cuestión. Si en Ética y politica se habían considerado tres concepciones que negaban la relación entre la ética y la política -la realista, la trágica y la dramática-, ahora dice que hay que añadir una cuarta concepción: la utópica, que no es otra cosa que la lucha constante por la democracia: «La actitud política genuinamente moral tiene que ser, a la vez, vigilante y entusiasta, des-encantada y presta al re-encantamiento, crítica y esperanzada, des-mitificadora y creyente, escéptica y utópica» ${ }^{6}$. En efecto, el moralista, en el mejor sentido del término -no el justiciero - no abandona la esperanza ni se deja vencer ante el desánimo. Aunque no hubiera ni un solo ejemplo en el mundo de virtud moral, habría que seguir defendiéndola, había enseñado Kant. Aranguren parece estar de acuerdo, Será muy crítico, muy lúcido para denunciar la distancia entre la democracia ideal y la (pseudo)democracia que se está instaurando. Una crítica, sin embargo, constructiva, en la medida en que no ceja en el empeño de señalar a otra realidad, también posible aunque inexistente, la democracia que debe ser.

Pero ¿qué debe ser la democracia?

En La democracia establecida: una critica intelectual ${ }^{7}$ se recogen los artículos que Aranguren fue escribiendo en El Pais desde 1975 hasta 1978. Se trata - dice él mismo- de «una crónica intelectual de la gestión -y no gestióndel gobierno Suárez». El acento está en la palabra «intelectual», pues las crónicas políticas pueden hacerse de distinta manera y desde diversas perspectivas. La crónica de Aranguren es decididamente intelectual, debe incluir dos cosas fundamentales: juicio crítico y una llamada a la cultura. Así, a lo largo de los artículos, se irá gestando, pues, «una concepción cultural y social de la política», que es la que debería orientar a la democracia.

Por una parte, la democracia debe saber «organizarse», la masa democrática, ya que estamos en democracia de masas -representativa y no directa-, debe ser «masa organizada». Esa organización, que recuerda la «institucionalización política de la moral», de la que hablaba en Ética y politica, implica, si se hace adecuadamente, más participación ciudadana, menos acumulación de poder, menos preponderancia de los partidos. «Ser demócrata requiere anteponer o, al menos, no posponer, el interés por la participación política a los meros ideales económicos inmediatos. El problema - problema real- de la democracia es un problema moral." Lo cual implica que la democracia es un quehacer constante, algo que siempre está «por hacer», que nunca es del todo alcanzable, como le ocurre también a la moral.

Antes de que se pusiera de moda el neoaristotelismo, de la mano de los comunitaristas, Aranguren optó por esa moral concebida como el fin de la naturaleza humana. Un fin particular y social, a la vez, pues la afirmación

\footnotetext{
"Ética de la felicidad y otros lenguajes», Obras Completas, 3, p. 525.

' Obras Completas, 5.
} 
de que el ser humano es un «animal político» sólo puede significar que, lo quiera o no lo quiera, es constitutivamente moral: tiene que construirse, hacerse su vida, no una vida solitaria, aislada de los demás, sino una vida social, comunitaria, política. Así entendida, la política es «una dimensión de la moral», como ya lo había visto Aristóteles.

Pero hay una segunda dimensión que el anhelo de perfección democrática, de la democracia como moral, no puede obviar. Es la democracia cultural. En realidad, la democracia cultural es un complemento de la democratización del poder o de la apertura a la participación. Las instituciones educativas, los medios de comunicación, la familia, la vida cotidiana deben democratizarse y completar, así, la democracia política. Si es lamentable la partitocracia, no lo es menos la delegación ciudadana de poderes y la entrega a una forma de vida «despolitizada». Aranguren adopta, en este punto, una postura firme $y$, de algún modo, contradictoria con su propia tesis de la institucionalización política de la moral: la concepción de la democracia como moral se traduce en un compromiso político total, pero distanciado de la política establecida, al margen de la organización real - no ideal- de la democracia.

El heterodoxo que siempre quiso ser Aranguren defiende, a tal respecto, su condición de marginal, pues sólo desde la heterodoxia y la marginalidad se mantiene la utopía de la moralidad de la política: «la idea que nosotros, los que no entramos en el juego y duelo político, tenemos de la política es muy otra: política como moral, política como cambio estructural y cambio cultural, política que empieza mucho antes del día que corresponde votar $\longrightarrow$ o forcejear para que se vote-y se prolonga mucho más allá de ese acto ritual, importante sin duda en la coyuntura actual, pero meramente como el urgente desatamiento final de lo que, a juzgar por lo que cuesta, bien atado se dejó ${ }^{8}$. Aranguren no quiso ser un político de nuevo estilo. Quiso ser, por el contrario, un intelectual al viejo estilo, un «moralista» en el sentido más clásico de los filósofos moralistas. Propugnó el compromiso, pero con la utopia, no con la imperfecta realidad. La institucionalización de la moral debía ser el fin de la política, en ello había que empeñarse, pero desde fuera, sin mezclarse ni entrar en el juego político.

\section{El intelectual moralista}

Si el fin de la política es la ética, ello significa «política para el cambio democrático, socioeconómico y cultural, y no para detentar poder $\mathrm{u}$ ostentar "representación"»".

Aranguren reconoce y deplora las servidumbres de la manera de hacer política cn un ticmpo donde todo tiene que someterse a las dinámicas del

"Ibid, p. 418.

'Mbid., pp. 418-419. 
mercado y la sociedad mediática. La política, como tantas otras cosas de nuestro tiempo, tampoco puede sustraerse al espectáculo, a la «representación» de sí misma. Lo cual no quiere decir que sea una "farsa»: es un espectáculo, una función. Lo importante y necesario es no confundir el espectáculo con la realidad.

La exigencia de espectáculo tiene sus ventajas, si las comparamos con el «hermetismo franquista». Pero, mantenicndo la misma comparación, ofrece asimismo desventajas. Con el franquismo, el silencio por lo menos podía inspirar respeto, el respeto hacia lo secreto y misterioso. En cambio, el espectáculo de ahora amenaza con lá pérdida de respetabilidad. Si sólo hay espectáculo, la credibilidad política se desvanece. Efectivamente, lo que a finales de los setenta y en plena transición democrática era visto como un peligro, un peligro de la aún frágil democracia que empezaba a andar, al cabo de los años $-\mathrm{y}$ no muchos - ha sido una palpable y evidente realidad. Vivimos tiempos no ya apolíticos, sino antipolíticos. Y una de las razones de haber caído en ello es la forma que ha ido adquiriendo la misma política. Su incapacidad por separar el espectáculo de la realidad y su afán por apuntarse al espectáculo sin más.

Pues bien, ante tal desilusionante panorama, el oficio del intelectual es cl del «vigilante», algo parecido - creo- a ese "público atento» que reclaman Almond y Verba. Dice Aranguren en un clarividente texto titulado El intelectual y la vigilancia de la vigilancia ${ }^{10}$ : "Cada vez va cxtendiéndose más la convicción de que es menester promover la formación de un libre conjunto de gentes políticamente comprometidas, políticamonte independientes y políticamente inapetentes de cargos públicos» ". A medida que envejece, Aranguren se vuclve más directo en sus críticas, más provocador, más insensato. Le pide al intelectual compromiso, pero independencia, le pide inapetencia de cargos. Sin duda, él lo practicó con beligerancia. Piensa que sólo así podrá el intelectual hacer su "oficio", que es el de udesmitologización política".

Empezar a hacer politica de verdad era, en la transición, un espléndido aliciente, pero también una tentación para el oportunista y el frívolo. Desde el principio, Aranguren ve con desconfianza «el milagro» de Suárez: un mal camino - decía - que ojalá dé buenos frutos. Demasiado posibilismo, demasiadas concesiones, demasiado utacitismo» y consensualismo, demasiadas conspiraciones y transacciones (la «transición» se ha convertido en una «transacción»). Sin mostrarse hostil a la Monarquía, la entiende como «cruz» en el doble sentido: "pecado originals de la democracia y carga insoportable para quien la representa ${ }^{12}$. Nos hemos conformado - dirá- con una democracia que sólo es «acatamiento de la Constitución», con una Constitución que «ya estaba constituida», con una izquierda "que ya no es revolucionaria».

\footnotetext{
Obras Completas, 5.

" Ibid., p. 387.

"Vease al respecto "La cruz de la monarquía española actual», Ohras Completas, 4.
} 
Con tales críticas, Aranguren representa realmente a esa cultura contestataria que presenció la transición alimentando desilusión y desencanto. Al cabo de los años y con visión más de conjunto, sin embargo, sus críticas no se muestran tan destructivas. Al contrario, Aranguren asume el papel de «criticón», de intelectual inorgánico - le gustaba repetir-, de heterodoxo y opuesto por principio al poder, porque no sabe concebir de otra forma al intelectual. En una conferencia que dio en el Congreso de los Diputados, invitado por el entonces presidente de la Cámara, Gregorio Peces-Barba, les dice a Sus Señorías que el intelectual, "hombre de auctoritas», no sabe qué hacer con el poder sino criticarlo, y que debe cstar «comprometido con la causa pública pero no en la praxis política». Sólo de esta forma se podrán conjugar las demandas de la política con las de la ética. Sólo así se podrán unir ética y política ${ }^{13}$.

Los grandes filósofos de la política moderna, Montesquieu, Locke, Rousseau, fueron, de algún modo, también «hetero-doxos", en el sentido que supieron proponer otra doxa, otros modos de vida. Tal vez, otros modos de hacer política, algo de lo que estamos tan necesitados. La definición del ser humano tan orteguiana, como «quehacer», impide entender el compromiso como algo cerrado, sumiso, disciplinario. El precio es la soledad. Aranguren se proclama repetidas veces «solidariamente solitario». No otra puede ser la actitud de quien se resiste a ceder y a ser complaciente porque no quiere dejar de ir por libre.

En una época que está siendo testigo de la puesta en cuestión de tantas convicciones que, pocos años antes, parecían incuestionables, Aranguren no muestra una personalidad vacilante: encarna sin miedo el papel obsoleto del intclectual comprometido. Piensa que aquel a quien le ha sido dado cultivar la inteligencia por encima de lo normal no tiene más remedio que sentirse en deuda con la sociedad. Su saber le obliga a prestar un servicio y a situarse frente a las cuestiones más complejas y difíciles. Una de ellas, consecuencia de todo lo que llevamos dicho: la desmoralización. Con su crítica, el intelectual quizá contribuya a hacer más profunda la falta de moral generalizada. Pero no hay otra forma de empujar hacia la transformación y el cambio. En efecto, los intelectuales «no servimos para nada, sólo para fastidiar -es decir, para la crítica- y para proponer modelos que se dirían irrealizables -es decir, para la utopía $\rightarrow{ }^{14}$.

\footnotetext{
1. Obras Completas, 5.

${ }^{4}$ Obras Completas, 4, p. 381.
} 


\section{Despolitización y desmoralización}

Una democracia plena es una democracia utópica. Cuando ese horizonte falta es difícil devolverle a la política su ser: recuperarla y sanarla de una despolitización que se ha hecho crónica y que parece irreversible. Aranguren la anuncia desde sus primeros pasos. Hay épocas que impulsan a la «despolitización». En nuestro caso fue ese «neotacitismo general» de los comienzos, que hizo perder rápidamente el propio proyecto: «entre la extrema derccha y la extrema izquierda nadie sabe dónde están los otros». No sólo cunde el desconcierto político, la falta de norte: la economía de mercado se ha hecho omnipresente y aceptada con complacencia, y «la desmoralización cunde en una España embarcada hacia el consumismo» ${ }^{15}$. Ante tal panorama, el intelectual se crige como «el moralista de una época ya sin moralismo».

Ante este panorama, la política en el sentido usual pierde relevancia, aunque como espectáculo no deje de estar presente en la vida pública. «Dentro de poco, si las cosas siguen así - profetiza Aranguren con total clarividencia-, nadie tomará en serio al gobierno de turno. $Y$ esto, repito, es muy grave. Un régimen político razonablemente asentado debe estar igualmente alejado de la sacralización y de la burlería» ${ }^{16}$.

El apartamiento de la Universidad por tantos años forzó al impulsor de la filosofía moral en nuestro país a dejar la filosofía política académica para encarnar una filosofía política viva y vivida, a la zaga de los acontecimientos de una de las épocas más intensas políticamente de la historia de España. Su postura repetidamente caracterizada como crítica y distante puede aparecer - y así se ha visto con frecuencia - como pretenciosa. No creo que lo fuera. Se dio cuenta muy pronto de que la «reforma moral» que este país necesitaba no vendría del brazo de una transición democrática que salió bien, pero fue decepcionante desde muchas expectativas y puntos de vista. Aranguren entendió que la moral no puede separarse de la cultura: también ésta debía reformarse, salir del desierto del franquismo y aprender de lo propio - de lo propio aprendible, que quizá no sea mucho ${ }^{17}-y$ de lo ajeno. Las estancias frecuentes en la California del mítico 68, además de empaparle de contracultura y, por lo tanto, de «contestación», le dieron la lucidez necesaria para no aplaudir en ningún momento una organización democrática que iba a adquirir rápidamente todos los vicios de las democracias más añejas.

A Aranguren sicmpre le gustó hablar de la moral en el doble sentido de «tener una moral» y «tener moral». Lo cual necesariamente conecta la ausencia de unos ideales morales con la «desmoralización». La reforma moral debe hacerse en ambos sentidos: recuperar los ideales de la izquierda - -no

\footnotetext{
${ }^{15}$ Obras Completas, 5, p. 392.

${ }^{16}$ Véase «España, una meditación política», Obras Completas, 3.

${ }^{17}$ Ibid., p. 701.
} 
los de antes, sino los que convienen ahora - y moralizar a la sociedad, y a la misma izquicrda, que bucna falta le hace. Para ello, hay que corregir la opinión de que la moral es un asunto privado. Quizá sea ésta la tesis fundamental que recorre toda la producción política de nuestro filósofo y que se perfila claramente en su seminario de 1963: la moral es insuficiente si no se realiza como moral social, política. Si esto es cierto, si la política tiene que moralizarse, alguien tiene que proponérselo. Es lo que conviene, precisamente, a la función de «moralista» que Aranguren asume: recuperar la dimensión social de la moral o, lo que es lo mismo, socializar, institucionalizar la moral. Descubrir los fallos morales $\multimap$ las inmoralidades - de la vida política, que son, en definitiva, las que desmoralizan a unos y a otros.

Quien esto propugnaba, sin embargo, no pretendió en ningún momento dárselas de «auténtico». Lo confesó explícitamente. Sabía que estaba representando un papel, haciendo también un espectáculo, y que esa misión le exigían una recreación $\mathrm{e}$ innovación constantes. Sabía que, como el buen intelectual que pretende ser, no tenía nada que hacer en la política, pero «sí, en cambio, y mucho, por encima y más allá, por debajo y más acá de la política». Por eso, aunque nunca ostentó ningún cargo público, pudo decir: «La verdad es que yo... no he hecho sino ocuparme de política, aun cuando, por supuesto, sin entrar en su "juego", porque no me va ese juego de la competición para ganar la apuesta que en él se disputa, el poder. Yo creo que los intelectuales tenemos poco que hacer en tal contienda.» 